\title{
Evaluation of Glutathione, Albumin and Ascorbic Acid Levels in Breast Cancer Patients
}

\author{
P. Faizal ${ }^{1}$, B. Satheeshan ${ }^{2}$, Milind Kumar ${ }^{3}$, A. K. Adarsh ${ }^{1}$, R. Shilpa ${ }^{1}$, P. Roshni ${ }^{1}$, T. Remya ${ }^{1}$, \\ K. T. Augusti ${ }^{1}$
}

${ }^{1}$ Department of Medical Biochemistry, School of Health Sciences, Kannur University, Thalassery, India; ${ }^{2}$ Department of Surgical Oncology, Malabar Cancer Centre, Thalassery, India; ${ }^{3}$ Department of Radiation Oncology, Malabar Cancer Centre, Thalassery, India. Email: faizal_tly@yahoo.com, gabas9@rediffmail.com,drmilindkumar@yahoo.com, adarshayadath@gmail.com, shilparaghavan@gmail.com,rosr1588@gmail.com,remyathayyullathil@gmail.com, ktaugusti@yahoo.co.uk

Received May 22 ${ }^{\text {nd }}, 2013$; revised June $26^{\text {th }}, 2013$; accepted July $5^{\text {th }}, 2013$

Copyright @ 2013 P. Faizal et al. This is an open access article distributed under the Creative Commons Attribution License, which permits unrestricted use, distribution, and reproduction in any medium, provided the original work is properly cited.

\begin{abstract}
Recently, an increase of global incidence has been observed for various types of cancers. Diet, lifestyle and environmental factors have an evident correlation to the development of breast cancer. Breast cancer is one of the leading causes of cancer related death in women. Several studies also revealed that excessive free radical generation and decreased antioxidant status had been implicated in cancer. These factors rekindled our interest upon the interaction of free radicals and antioxidants and hence the present study was undertaken to evaluate the significance of non enzymic antioxidants: glutathione, albumin and ascorbic acid levels in breast cancer patients. The study population was divided into 3 groups as follows: Group I control subjects (age group 21 - 60), Group II: breast cancer Patients (age group 21 35 ) and Group III breast cancer patients (age group 36 - 60). Highly statistically significant increases in glutathione, albumin and ascorbic acid levels were observed in Group I as compared to other groups. No significant differences in glutathione, albumin and ascorbic acid levels were observed in a group comparison between Group II and Group III. This relative decline of non enzymic antioxidants in breast cancer patients may be due to an increased generation of reactive oxygen species or free radicals. The results obtained emphasize the need of more detailed study involving a large number of newly detected cancers for evaluating the role of these antioxidant parameters in the prevention of cancer.
\end{abstract}

Keywords: Free Radicals; Antioxidants; Reactive Oxygen Species

\section{Introduction}

Cancer is a class of diseases or disorders characterized by uncontrolled division of cells and the ability of these cells to invade other tissues, either by direct growth into adjacent tissue through invasion or by implantation into distant sites by metastasis [1]. Diet, lifestyle and environmental factors contribute to the etiology of cancer. It has been estimated that 35 percent of cancer deaths may be related to dietary factors. Almost all cancers (80\% $90 \%$ ) are caused by environmental factors, and of these, $30 \%-40 \%$ of cancers are directly linked to the diet $[2,3]$. Oxygen radicals are continuously formed in all living organisms, with deleterious effects that lead to cell injury and death. Production of oxidative species occurs under physiological conditions at a controlled rate, but it is dramatically increased in conditions of oxidative stress. Cell damage caused by free radicals appears to be a major contributor in aging and degenerative diseases of aging such as cancer, cardiovascular disease, cataracts, compromised immune system, rheumatoid arthritis and brain dysfunction [4]. Free radicals have been implicated in the pathogenesis of at least 50 diseases. Fortunately, free radical formation is controlled naturally by various beneficial compounds known as antioxidants. Antioxidants are capable to stabilize, deactivate or scavenge free radicals before they attack cells. Antioxidants play an important role in maintaining optimal cellular and systemic health and well-being of the body. Antioxidant action includes free radical scavenging capacity, inhibition of lipid peroxidation, metal ion chelating ability and reducing capacity [5].

Recently, an increase of global incidence has been observed for various types of cancers [6]. Diet, lifestyle and environmental factors have an evident correlation to the development of breast cancer. Breast cancer is one of the leading causes of cancer-related death in women [7]. 
Several studies also revealed that excessive free radical generation and decreased antioxidant status had been implicated in cancer [8]. These factors rekindled our interest upon the interaction of free radicals and antioxidants and hence the present study was undertaken to evaluate the significance of non enzymic antioxidants: glutathione, albumin and ascorbic acid levels in breast cancer patients.

\section{Materials and Methods}

Cancer patients registered at the Malabar Cancer Centre, Thalassery, were chosen as the patient group (age: 21 60). A total of 60 breast cancer patients as adjudged from clinical features, histopathological and biochemical investigations were selected for the study. As control group 30 normal healthy subjects of the same age group as that of the cancer patients were taken. Participants suffering from any diseases that may interfere with the study were excluded. The work has been carried out at the Malabar Cancer Centre, Thalassery and Department of Medical Biochemistry, School of Health Sciences, Kannur University. Ethical committee from both the collaborating institutions approved the study. An informed consent for the study was obtained from each participant. The Clinical proforma was given to each patient to collect data such as height, weight, diet pattern, previous history of illness etc. Patients suffering from any disease that may interfere with the study were excluded. A log book was maintained for the patients. The study population was divided into 3 groups as a group I control subjects (age group 21 - 60), Group II: breast cancer Patients (age group 21 - 35) and Group III breast cancer patients (age group 36 - 60). $2 \mathrm{ml}$ blood sample was taken for the analysis from each of the control subjects and the patients. Plasma was separated and assayed using standard methods. The analysis of Glutathione [9] (DTNB method), Albumin [10] (BCG method), and Ascorbic acid [11] (2,6-Dichlorophenol-indophenol method) were carried out using standard methods. The statistical analysis was performed by paired students " $\mathrm{t}$ " test using Software Package for Social Sciences (SPSS 18).

\section{Results and Discussion}

In the present study, significant decreases in the plasma levels of glutathione, albumin and ascorbic acid were observed in breast cancer patients undergoing treatment as compared to control subjects (Tables 1 and 2). This relative decline of non enzymic antioxidants in breast cancer patients may be due to an increased generation of reactive oxygen species or free radicals. Non enzymic metabolic antioxidants are generally decreased in various types of cancers. Intergroup comparison of plasma levels of glutathione, albumin and ascorbic acid in between
Table 1. Comparison between control group and case group.

\begin{tabular}{cccc}
\hline Parameters studied & $\begin{array}{c}\text { Group I } \\
(\mathbf{3 0 )}\end{array}$ & $\begin{array}{c}\text { Group II } \\
\mathbf{( 3 0 )}\end{array}$ & $\begin{array}{c}\text { Group III } \\
\mathbf{( 3 0 )}\end{array}$ \\
\hline Glutathione (mg/dL) & $38 \pm 7.2$ & $22 \pm 9.1$ & $20 \pm 10.3$ \\
Albumin (g/dL) & $4.5 \pm 0.3$ & $3.0 \pm 0.44$ & $2.9 \pm 0.5$ \\
Ascorbic acid (mg/dL) & $0.9 \pm 0.15$ & $0.55 \pm 0.14$ & $0.45 \pm 0.1$ \\
\hline
\end{tabular}

Table 2. Group comparison and level of significance.

\begin{tabular}{ccc}
\hline Parameter & $\begin{array}{c}\text { Group } \\
\text { Comparison } \\
\text { between }\end{array}$ & $\begin{array}{c}\text { Level of } \\
\text { Significance } \\
\text { P values }\end{array}$ \\
\hline \multirow{2}{*}{ GLUTATHIONE } & I and II & $<0.005$ \\
& I and III & $<0.005$ \\
& II and III & NS \\
ALBUMIN & I and II & $<0.005$ \\
& I and III & $<0.005$ \\
ASCORBIC ACID & II and III & NS \\
& I and II & $<0.005$ \\
& I and III & $<0.005$ \\
& II and III & NS \\
\hline
\end{tabular}

Highly statistically significant increases in glutathione, albumin and ascorbic acid levels were observed in Group I as compared to other groups. No significant differences in glutathione, albumin and ascorbic acid levels were observed in a group comparison between Group II and Group III.

different age groups in breast cancer patients shows that there is no characteristic difference in significance. Epidemiological evidence shows that people who consume large amounts of fruits and vegetables have reduced risk of many types of cancer. Antioxidant nutrients present in various fruits and vegetables that one may consume may be responsible for some of the protective effects observed in control group [12-14], (Figure 1 [15]).

\section{Conclusion}

Oxidative stress arises when there is an imbalance between oxygen free radical formation and scavenging by antioxidants. Excess generation of free radicals causes damage to cellular biomolecules which results in lipid peroxidation, mutagenesis and carcinogenisis. Their chief danger comes from the damage they can do when they react with important cellular components such as DNA, or the cell membrane. To prevent free radical damage, the body has a defense system of antioxidants. Antioxidants act as scavengers of free radicals and promote cell to carry out apoptosis. This study was aimed to evaluate the status of glutathione, albumin and ascorbic acid in cancer patients. Statistical analysis showed significant decline in these metabolic antioxidants in cancer patients when compared to control. It remains unclear whether the individuals with low antioxidant levels are predisposed to malignancy or whether in malignancy such a condition of low antioxidant levels is occurring. The results obtained 


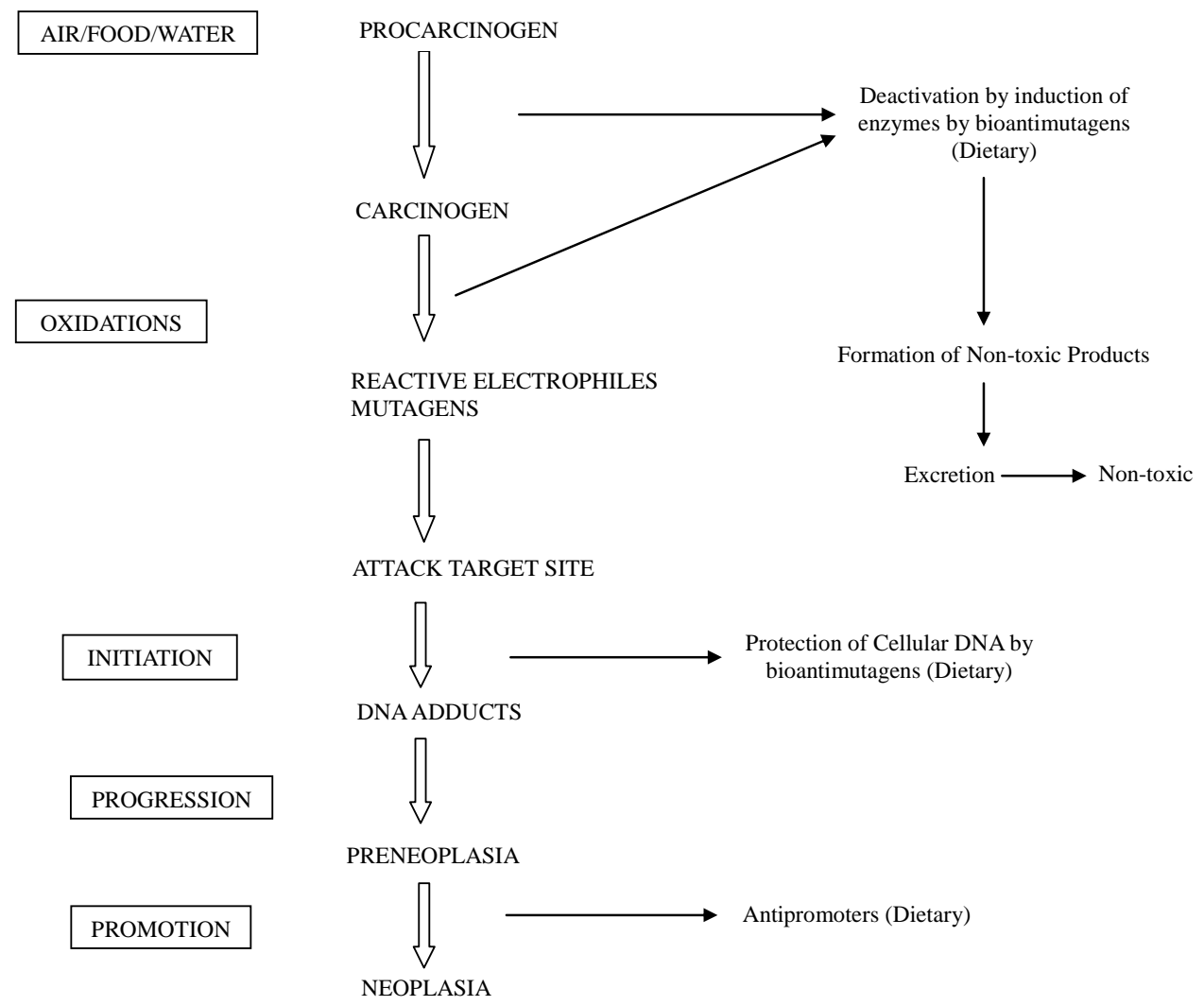

Figure 1. Role of dietary factors in carcinogenic process [15].

emphasize the need of more detailed study involving a large number of newly detected cancers for evaluating the role of these antioxidant parameters in the prevention of cancer.

\section{REFERENCES}

[1] P. Anand, A. B. Kunnumakkara, et al., "Cancer Is a Preventable Disease That Requires Major Lifestyle Changes," Pharmaceutical Research, Vol. 25, No. 9, 2008, pp. 2097-2116. doi:10.1007/s11095-008-9661-9

[2] T. J. Key, "Fruit and Vegetables and Cancer Risk," British Journal of Cancer, Vol. 104, No. 1, 2011, pp. 6-11. doi:10.1038/sj.bjc.6606032

[3] A. Cappellani, M. Di Vita, A. Zanghi, A. Cavallaro, G. Piccolo, M. Veroux, M. Berretta, M. Malaguarnera, V. Canzonieri and E. Lo Menzo, "Diet, Obesity and Breast Cancer: An Update," Frontiers in Bioscience (Scholar Edition), Vol. 4, 2012, pp. 90-108.

[4] K. Z. Guyton and T. W. Kensler, "Oxidative Mechanisms in Carcinogenesis,” British Medical Bulletin, Vol. 49, No. 3, 1993, pp. 523-544.

[5] U. Sathyanarayan and U. Chakrapani, "Biochemistry," Books and Allied (P) Ltd., 3rd Edition, Kolkata, 2007, pp. 655-661.

[6] A. Jemal, F. Bray, M. M. Center, J. Ferlay, E. Ward and D. Forman, “Global Cancer Statistics,” CA: A Cancer Journal for Clinicians, Vol. 61, No. 2, 2011, pp. 69-90.
[7] A. Jemal, T. Murray, E. Ward, A. Samuels, R. C. Tiwari, A. Ghafoor, E. J. Feuer and M. J. Thun, "Cancer Statistics,” CA: A Cancer Journal for Clinicians, Vol. 55, No. 1, 2005, pp. 10-30. doi:10.3322/canjclin.55.1.10

[8] M. Dizdaroglu, P. Jaruga, M. Birincioglu, et al., "FreeRadical-Induced Damage to DNA: Mechanisms and Measurement," Free Radical Biology \& Medicine, Vol. 32, 2002, pp. 1102-1115.

[9] M. S. Moron, J. W. Depierre and B. Mannervik, "Levels of Glutathione, Glutathione Reductase and Glutathione STransferaseactivities in Rat Lung and Liver," Biochimica et Biophysica Acta, Vol. 582, No. 1, 1979, pp. 67-78. doi:10.1016/0304-4165(79)90289-7

[10] A. O. Lawal, B. Kolude, B. F. Adeyemi, J. O. Lawoyin and E. E. U. Akang, "Relationship between Serum Albumin and Oral Epithelial Cancers in Patients Seen at a Nigerian Tertiary Hospital,” African Journal of Biomedical Research, Vol. 13, No. 3, 2010, pp. 225-229.

[11] S. T. Omaye, T. P. Turbull and H. C. Sauberchich, "Selected Methods for Determination of Ascorbic Acid in Cells, Tissues and Fluids," Methods in Enzymology, Vol. 6, 1979, pp. 3-11. doi:10.1016/0076-6879(79)62181-X

[12] S. Kumar, "Free Radicals and Antioxidants: Human and Food System," Advances in Applied Science Research, Vol. 2, No. 1, 2011, pp. 129-135.

[13] M. Valko, D. Leibfritz, J. Moncol, M. T. D. Cronin Milan Mazur and J. Telser, "Free Radicals and Antioxidants in Normal Physiological Functions and Human Disease," The International Journal of Biochemistry \& Cell Biology, 
Vol. 39, No. 1, 2007, pp. 44-84.

doi:10.1016/j.biocel.2006.07.001

[14] A. L. Ortega, S. Mena and J. M. Estrela, "Glutathione in Cancer Cell Death,” Cancers, Vol. 3, No. 1, 2011, pp.
1285-1310.

[15] K. Krishnaswamy and K. Polasa, "Diet, Nutrition and Cancer: The Indian Scenario,” Indian Journal of Medical Research, Vol. 102, No. 5, 1995, pp. 200-209. 